\title{
Public-Private Partnerships: Task Interdependence and Contractibility
}

\author{
Bin R. Chen and Y. Stephen Chiu* ${ }^{\dagger}$
}

February 1, 2010

\begin{abstract}
We examine the proper scope of public-private partnerships in the context of a project consisting of two tasks, building and operation of a facility. We investigate the optimal arrangement regarding bundling versus unbundling and private ownership versus public ownership. Like Bennett and Iossa (2006), we assume that the innovative activity in the building stage has impacts on, among other things, the subsequent operational cost. We relax the nature of task interdependence and study different contractual frameworks. The general insight is that given limitations in contractibility, contrary to common sense, complementarity between tasks favors unbundling over bundling.

Keywords: Complementarity; Substitutability; Incomplete contracts; Publicprivate partnership.

JEL classification: D23; H11; L33.
\end{abstract}

\section{Introduction}

Nowadays, it is common across countries that governmental agencies collaborate with the private sector to deliver public services; in some cases, even the whole project is contracted out to a single firm that takes responsibilities for all involved tasks, such as both building and maintaining the facility. In the literature of public-private

\footnotetext{
${ }^{*}$ Chen: School of Economics and Finance, The University of Hong Kong, Pokfulam Road, Hong Kong, P.R.China. E-mail: chinabin@hku.hk. Chiu (corresponding author): School of Economics and Finance, The University of Hong Kong, Pokfulam Road, Hong Kong, P.R.China. E-mail: schiu@econ.hku.hk, Tel: +852 2859-1056, Fax: +852 2548-1152.

${ }^{\dagger}$ We are grateful to a coeditor and two referees for comments that have significantly improved the paper. We would also like to thank Kong-pin Chen, Eric S. Chou, and Ping Lin for discussions and participants in the Far East Econometric Society Meeting, Tokyo, 2009, for comments. Any remaining errors are our own. Financial support from the Hong Kong Research Grants Council (HKU742407H) is acknowledged.
} 
partnerships (PPPs), as this practice is usually referred to, two issues have received much attention: multitasking and investment contractibility. Given multiple tasks such as building and subsequent maintenance of a facility - an important question is whether the tasks should be handled by a single consortium (in case of bundling) or by two separate firms (in case of unbundling). This question of course depends on the contractibility of and the relationship between tasks, as is shown in the literature. In this paper, we further examine this question, extending the existing work.

Our paper is closely related to the piece by Bennett and Iossa (2006), in which two non-contractible innovation activities (or investments in short), one in the building stage and the other in the operating stage, are supposed to reduce cost and enhance quality. Assuming a sort of task externality so that the investment in the building stage may increase or decrease the cost in the operating stage, the paper shows that, with positive externality, it is more efficient for the tasks to be bundled; with negative externality, it is more efficient for the tasks to be separated. In another paper where both operational costs and service quality are contractible, Martimort and Pouyet (2008) also show similar results.

However, the relationship between tasks can be richer. They may be interdependent, being substitutes, such that making more of one investment will decrease the returns of making more of another investment. For example, a hospital may be built in a more specified manner so that, while the subsequent operational cost is generally lower (i.e., positive externality), further enhancement of quality or alternation of usage would be more difficult to achieve. The two tasks may be interdependent, sharing complementaries, such that making more of one investment will increase the returns of making more of another investment. For instance, a school may be built with better-quality and more-expensive-glass windows so that, whereas the subsequent operational cost is generally lower (i.e., positive externality), an increase in guard services during the operating stage may be more valuable as it prevents a greater loss from pupils' vandalism. In this paper, we examine the implications of task interdependence that allows for substitutability and complementarity; another novelty is the way we model investment contractibility, which will be clear in a moment.

To briefly illustrate how task interdependence matters, let us revisit the contractual framework in Bennett and Iossa (2006). Consider the case of task complementarity. In case of unbundling, the builder could bargain with the manager or the government. After the bargaining, the builder could share the benefits generated by the manager's investment, while not bearing any cost incurred by such investment. Because of complementarity, a higher building investment leads to a higher operating investment, yielding a greater net surplus to be split. Anticipating more rents to 
be extracted from the manager's investment, the builder has a greater incentive to invest. As a result, investment complementarity helps mitigate the underinvestment problem of the builder under unbundling. In the case of bundling, on the contrary, when investing in the building stage, the consortium will internalize not only the benefits but also the costs of subsequent investment, resulting in a dampened investment incentive on his part. ${ }^{1}$ Thus, at the margin, task complementarity favors unbundling, relative to bundling. Notice that because task complementarity can be viewed a special kind of positive externality, this result sheds new, somewhat counter-intuitive, light to the issue on PPPs.

In the main body of this paper, we focus on a contractual framework somewhat different from Bennett and Iossa (2006); we assume that the operation task becomes contractible subsequent to the building stage. Examples from construction sectors show that the contract on service provision is usually finalized until the infrastructure is in place. Moreover, even though a contract specifies the operating task in advance of the project, it may still be subject to adaptation and renegotiation after the construction is carried out. These observations are consistent with the idea that the requirements regarding the successive operation task become revealing as time goes by. ${ }^{2}$ We think that the framework of "interim contractibility" is worthwhile studying (see Iossa and Martimont, 2008 for discussions). To check the robustness of our results, we also examine the role of task interdependence in the incomplete contracting framework as in (Bennett and Iossa, 2006) and in complete contracting frameworks as in (Martimort and Pouyet, 2008; Schmitz, 2005).

In the framework of interim contractibility, our findings suggest that under private ownership, task externality, as well as task interdependence, still plays an important role in shaping the trade-offs between integration and separation. In particular, task complementarity favors the builder's ownership, but disfavors the consortium's ownership. The intuition is much similar to what we have discussed with respect to Bennett and Iossa's model, but the difference is that, given the interim contractibility, the negotiation on the ex post adoption of the operating investment is replaced by the negotiation on the ex ante approval prior to its choice. Through such bargaining, either the builder or the consortium shares the benefits (generated by the operating investment), and the gains are in turn dependent on his own investment in the building stage. On the other hand, we find that under public ownership, the

\footnotetext{
${ }^{1}$ Without loss of generality, we use the pronoun "she" to represent the government, and use the pronoun "he" to represent the firms (or agents).

${ }^{2}$ One fact, which is pointed out by Neher (1999), is that as the project matures, more human capital is converted into physical assets, making the alienable (contractible) elements of the project manifested.
} 
difference between integration and separation vanishes. The reasons trace to the interim contractibility of the operating investment as well as the veto power of the government on the ex post adoption of the building investment.

Besides the bundling versus unbundling problem, this paper also reexamines, in different contractual frameworks, whether the project should be privately owned or publicly owned. In general, our main results are consistent with those in Bennett and Iossa (2006), where a larger residual value effect and a smaller social value effect favor private ownership, and public ownership is favored when the opposite is true.

The present paper belongs to the strand of literature that investigates either desirable contracting schemes in the public-private partnership (e.g., Hart, 2003; Martimort and Pouyet, 2008; Bentz et al, 2001; Iossa and Martimort, 2008; Hoppe and Schmitz, 2008) or optimal ownership structures in the public-private partnership (e.g., Hart et al, 1997; Francesconi and Muthoo, 2006; Besley and Ghatak, 2001; Bennett and Iossa, 2006). But none of these papers has addressed exactly the same questions as we do here.

Our research is also related to the papers that study the holdup problem of sequential specific investments. Like what we assume here, Smirnov and Wait (2004) assume that, if an initial investment is made, contracting on the subsequent investment becomes possible. But they address a different question about whether the parties should make investments simultaneously or sequentially. Another relevant paper is De Fraja (1999), who find that if specific investments are made sequentially, ex ante contracting can solve the holdup problem even though there exist two-sided direct externalities across investments. ${ }^{3}$ Here, we study the interrelationship among three parties (namely, two investors and one principal), instead of between two, leading to different results.

The remainder of this paper is organized as follows. Section 2 presents the main model. Section 3 examines the optimal regime when the operation task becomes contractible subsequent to the building stage. Section 4 briefly discusses the issue in the framework used by Bennett and Iossa (2006), in which all tasks are noncontractible. Section 5 addresses the issue from a complete contract perspective. Section 6 concludes.

\footnotetext{
${ }^{3}$ Disagreeing with De Fraja (1999), Che (2000) argues that the contract suggested by De Fraja (1999) provides almost no incentive for specific investments when they exhibit sufficiently large direct externalities. Che (2000) proposes an alternative contract. For other papers on the sequential specific investments, please see Lulfesmann (2004) etc.
} 


\section{Model}

A governmental agency (hereafter, the government) is contemplating a project that, upon its completion, will enhance social benefit. The project consists of two sequential tasks, namely, "building" and "operating" a facility. The facility of a minimum standard can be built at a certain cost, and the completed facility can be operated at a certain cost as well. However, prior to the actual building, the builder can undertake an innovative activity that increases both the social benefit and the residual value of the facility, affecting the costs and efficacy of the following operation task (the residual value refers to the value of the facility to the owner upon the expiration of the project). Likewise, subsequent to the completion of building but prior to the actual operation, the manager can undertake an innovative activity that reduces the operational cost and increases the social benefit. We use $a$ and $e$ to denote the level (also the cost) of innovative activity in the building stage and in the operating stage, respectively. The government can either engage with the builder and the manager who are separately in charge of these two tasks, or with a consortium who takes care of both tasks. ${ }^{4}$ In either case, these agents are risk-neutral, so is the government.

Let $C(a, e)$ be the operational cost of the facility borne by the manager (or operator) in the operating stage. We assume that

$$
C(a, e)=C_{0}-d(a, e)
$$

where $C_{0}$ is the positive default cost, and $d(a, e)$ is the reduction of operational cost caused by the investments of $a$ and $e$. The function $d(a, e)$ is three-order differentiable, satisfying the following properties:

(i) $d(0,0)=0$.

(ii) $d_{2}(a, e)>0, d_{2}(a, 0)=\infty, d_{2}(a, \infty)=0, d_{22}(a, e)<0$.

(iii) If $d_{1}(a, e)>0$, then $d_{1}(0, e)=\infty, d_{1}(\infty, e)=0, d_{11}(a, e)<0$; if $d_{1}(a, e)<0$, then $d_{1}(0, e)=0, d_{1}(\infty, e)=-\infty, d_{11}(a, e)<0$.

This operational cost function generalizes that in Bennett and Iossa (2006), since we allow not only the direct effect of $a$ on the operational cost but also the crossterms between $a$ and $e$. In particular, if $d_{1}(a, e)>0$, $a$ reduces the operational

\footnotetext{
${ }^{4}$ We assume that when the builder and the manager form a consortium, they act as one person. This assumption is also used in Bennett and Iossa (2006), as well as in the main part of Martimort and Pouyet (2008) that we will contrast with in Section 5. This view of integration, however, is different from Grossman and Hart (1986). In general, integration and non-integration are different ownership structures, and there should still be incentive problems within an integrated firm. An alternative interpretation of our case is that we are indeed asking whether the two tasks should be assigned to one agent or to two separate agents.
} 
cost; if $d_{1}(a, e)<0, a$ increases the operational cost. These positive and negative externalities are studied in Bennett and Iossa (2006). Our focus, however, is the role of cross partials. If $d_{12}(a, e)>0, a$ and $e$ are complementary investments; in this case, an increase in $a$ increases the marginal benefit of $e$. It is also conceivable that $d_{12}(a, e)<0$, i.e., $a$ and $e$ are substitute investments. In this case, an increase in $a$ reduces the marginal benefit of $e$. Note that in Bennett and Iossa (2006), $d_{12}(a, e)$ is assumed to be zero. In our more generalized framework, there are four different possible relationships between $a$ and $e$ : (i) $d_{1}(a, e)>0, d_{12}(a, e)>0$; (ii) $d_{1}(a, e)>0$, $d_{12}(a, e)<0$; (iii) $d_{1}(a, e)<0, d_{12}(a, e)>0$; and (iv) $d_{1}(a, e)<0, d_{12}(a, e)<0$ (the knife-edge cases with zero derivatives being omitted).

Three remarks are in order. First, we are agonistic as to which technology regime is more prevalent; in any case, this is an empirical issue and can only be settled by a careful examination of the public project we have at hand. Second, instead of studying the choice among these four technology regimes, we address the following question: given the technology regime, what kind of public-private relationship is most efficient. Third, to facilitate exposition, we will use the following nomenclature unless otherwise stated. Task or investment externality refers to the case that $d_{1}(a, e)$ is nonzero; in particular, positive (negative) externality refers to where $d_{1}(a, e)>0$ $\left.\left(d_{1}(a, e)<0\right)\right)$. Task or investment interdependence refers to the case that $d_{12}(a, e)$ is nonzero; in particular, complementarity (substitutability) refers to where $d_{12}(a, e)>$ $0\left(d_{12}(a, e)<0\right)$.

Next we assume that the project generates the following social benefits: ${ }^{5}$

$$
B(a, e)=B_{0}+u(a)+v(e)
$$

where $B_{0}$ is the positive default benefit; $u(0)=v(0)=0 ; u^{\prime}(a), v^{\prime}(e)>0 ; u^{\prime \prime}(a), v^{\prime \prime}(e)<$ $0 ; u^{\prime}(0)=v^{\prime}(0)=\infty ; u^{\prime}(\infty)=v^{\prime}(\infty)=0$.

The residual value of the facility is claimed and taken away by the owner when the project expires. For simplicity, we continue to assume that this value depends on $a$ but not on $e$; given the choice of $a$, the residual value equals

$$
R(a)=R_{0}+t(a)
$$

where $R_{0}$ is the positive default residual value, $t(0)=0 ; t^{\prime}(a)>0, t^{\prime \prime}(a)<0$; $t^{\prime}(0)=\infty ; t^{\prime}(\infty)=0$. We make an assumption on the relationship between $t(a)$ and

\footnotetext{
${ }^{5}$ We maintain the functional form in Bennett and Iossa (2006) for simplicity. It is possible to consider a more general functional form of social benefit by allowing the cross-terms between $a$ and $e$. One can show that this assumption is not crucial in driving the main results.
} 
$d(a, e)$.

A1 $t^{\prime}(a)+d_{1}(a, e)>0$.

This assumption implies that, although we entertain the possibility that $a$ increases the operational cost, this negative externality is only moderate. ${ }^{6}$

Notice that the first-best investments $\left(a^{*}, e^{*}\right)$ satisfy the following two equations:

$$
u^{\prime}\left(a^{*}\right)+t^{\prime}\left(a^{*}\right)+d_{1}\left(a^{*}, e^{*}\right)=1
$$

and

$$
v^{\prime}\left(e^{*}\right)+d_{2}\left(a^{*}, e^{*}\right)=1
$$

We assume that unique, interior solutions to these two equations exist.

Assume that both innovative activities $a$ and $e$ are observable so that, once chosen, there is no ambiguity about their values. These investments, however, could be nonverifiable so that no contracts can be made contingent on them. Whereas these assumptions are standard in the literature, what is novel here is that we assume that $e$ is interim contractible; that is, $e$ is contractible if and only if $a$ has been chosen. The underlying reason is that once the facility is built, such fundamentals as operational costs or social benefits become describable. ${ }^{7}$

Figure 1 about here

The game can be summarized by a sequence of events by the time line in Figure 1. At time 0 , the regime is determined. The various regimes include: separation with builder ownership $(S B)$, separation with manager ownership $(S M)$, separation with public ownership $(S P)$, integration with consortium ownership $(I C)$, and integration with public ownership $(I P)$ (where separation means unbundling and integration means bundling). Moreover, the government can only sign contracts that specify the minimum standards and promise fixed payments based on such default values as $C_{0}, B_{0}$, and $R_{0}$.

At time 0.5, investment $a$ is chosen. At time 1, after the chosen $a$ becomes observable, the builder (or the consortium) bargains with the owner over the adoption

\footnotetext{
${ }^{6}$ Similar assumption is used in Bennett and Iossa (2006). As will be clear, this assumption ensures that if the consortium owns the facility it is always in his interest to adopt $a$.

${ }^{7}$ Since we here do not assume any contracting frictions due to limited liability or risk aversion, a contract conditional on the level of operational cost is equivalent to that conditional on the level of $e$.
} 
of $a$. At time 2, the requirements on the operation task become revealed. Two events take place in a sequence: the government may first negotiate with the builder (or the consortium) on the subsequent adoption of $e$, and then contracts with the manager (or the consortium) on the level of $e$ to be chosen. ${ }^{8}$ At time 2.5, investment $e$ is chosen. At time 3, in case no agreement on the adoption of $e$ was reached at time 2 , the involved parties may bargain over the adoption of $e$. (Note that, while not occurring in the equilibrium path, the negotiation problem at time 3 determines the threat points for the negotiation problem at time 2.) At time 4, the contractual relationship between the government and the agents ends, and all the payoffs are realized. As explained, we assume that bargaining is always bilateral, despite three stakeholders under some regimes. ${ }^{9}$ We also note that the costs of investing $a$ or $e$ are sunk once the investment is made.

We apply the Nash bargaining solution to calculate each party's payoff in a negotiation; the two involved parties are assumed to have equal ex post bargaining power. Two special features of the bargaining solution are worth mentioning. First, to best compare and contrast our results, we follow Bennett and Iossa (2006) in assuming that if the investor is the owner, he cannot commit not to implement his own investment (i.e., his investment will be implemented without going through any bargaining); on the other hand, whenever the investor and the owner are not the same, they will negotiate on the adoption of the investment. Second, we assume that, the owner cannot unilaterally use the innovation without the agreement of the investor. ${ }^{10}$

We end with a comment about the government's objective. Here we assume that the government's payoff is equal to the social benefit minus payments made to the firm(s), plus the residual value if she is also the owner. In this regard, her objective is different from a benevolent social planner in typical welfare analysis. It should be noted that, however, in the framework of interim contractibility, regardless of the ownership and organizational structure, the government will succeed in ensuring the investment and adoption of the efficient level of $e$. Given $a$, the efficient level of $e$,

\footnotetext{
${ }^{8}$ Here we implicitly assume that, in case of unbundling, the solo manager will be recruited by the government at time 2 .

${ }^{9}$ In the builder ownership case, for instance, the stakeholders are the builder, the operator, and the government. One can imagine a scenario in which the three parties bargain among themselves at some point of time. Whereas such a setting is reasonable and deserves studies, it is beyond the scope of this paper.

${ }^{10}$ It should be noticed that this assumption, while also used in Bennett and Iossa (2006), is in contrast with Aghion and Tirole (1994). An underlying reason is that the investment has some component of human capital, which makes it impossible to materialize without its investor's final cooperation.
} 
denoted by $\widetilde{e}(a)$, is given by

$$
v^{\prime}(\widetilde{e}(a))+d_{2}(a, \widetilde{e}(a))=1
$$

The reason is that, since $e$ becomes contractible at time 2 , it is the involved parties' common interest to maximize the surplus to be divided in the corresponding negotiation.

\section{Interim contractibility}

\subsection{Investments under private ownership}

In this subsection, ownership is assumed to be allocated to some investor. There are three possible regimes - separation with builder ownership, separation with manager ownership, and integration with consortium ownership. Here, we do not consider the manager-ownership case, since it is at least weakly dominated by some other regime. The intuition is simple. Given that $e$ is interim contractible, the manager is always provided with the right incentive to invest. While not improving this incentive further, conferring ownership to the manager complicates matters due to the likelihood that the builder's investment incentive is reduced. Thus, so long as no confusion is caused, we refer interchangeably to the builder-ownership case and to the separation case under private ownership.

\subsubsection{Ownership by the builder}

Suppose that the tasks of building and operation are contracted out separately, and the builder owns the facility. By using backward induction to solve this game, we first analyze the operating stage. Figure 2 illustrates the timing of the events that occur in this stage. In particular, since the builder has the veto power on the adoption of investment $e$, he may negotiate with the government on this issue at the end of operating stage (i.e., time 3). ${ }^{11}$ However, given the interim contractibility of $e$, such negotiation may not necessarily happen, if the government could solicit the builder's agreement on the adoption of $e$ prior to its choice. In this sense, the negotiation on the ex ante approval of $e$ (at time 2) replaces the negotiation on the ex post adoption

\footnotetext{
${ }^{11}$ We assume that the government would represent the manager in the negotiation with the builder, whenever it occurs. The justification is that, given the interim contractibility of $e$, no matter whether the government or the manager is involved in a bargaining, their interests could be perfectly aligned prior to the bargaining. It also explains why both the social benefit and the operational cost are considered in such a bargaining.
} 
of $e$ (at time 3). To better analyze the former negotiation, we first study the latter negotiation (which occurs only in case that the former negotiation breaks down).

Figure 2 about here

time 3 We only consider the subgame following the history that no agreement was reached at time 2 . In this subgame, given the adopted $a$ and the chosen $e$, the builder will negotiate with the government on the adoption of $e$. If such negotiation breaks down and $e$ is not adopted, in the operating stage, the builder gains nothing, while the government pays the operational cost $C(a, 0) ;{ }^{12}$ however, if the agreement is achieved, the net surplus created equals $[v(e)-C(a, e)+C(a, 0)]$. Through the Nash bargaining, they will agree to adopt $e$, dividing the net surplus equally. Thus, the builder's gains from such bargaining, denoted by $f_{b}^{O}$, are calculated as follows.

$$
f_{b}^{O}=\frac{1}{2}[v(e)-C(a, e)+C(a, 0)] .
$$

time 2.5 The manager will invest the level of $e$ which is exactly specified in the contract (signed at time 2).

time 2 At time 2, there are two events occurring in a sequence: the government first negotiates with the builder on the subsequent adoption of $e$, and then signs a complete contract with the manager on the choice of $e$.

To analyze the negotiation between the government and builder, we first consider the case in which these two parties fail to achieve an agreement on the choice and adoption of $e$ at time 2. In this case, foreseeing the negotiation that will happen at time 3 , the government will force the manager to choose a level of $e$ (denoted by $e_{S B}^{O}$ ) that maximizes her payoff, which is the social benefit of $e, v(e)$, minus the payment to the builder, $\frac{1}{2}[v(e)-C(a, e)+C(a, 0)]$, as well as the payment to the manager,

\footnotetext{
${ }^{12}$ The operational cost is directly borne by the manager, but it could be transferred from the government to the manager through the complete contracting on $e$. So given that no contracting friction exists and that the manager always ends up with a payoff of 0 , the government indirectly bears all the costs incurred in the operating stage.
} 
$[e+C(a, e)] \cdot{ }^{13}$ Thus, the choice of $e_{S B}^{O}$ satisfies

$$
\frac{1}{2}\left[v^{\prime}\left(e_{S B}^{O}(a)\right)+d_{2}\left(a, e_{S B}^{O}(a)\right)\right]=1
$$

Note that $e_{S B}^{O}(a)$ is necessarily smaller than the efficient level $\widetilde{e}(a)$, and that $e_{S B}^{O}(a)$ will help define the threat points of the negotiation occurring immediately before.

Now consider the case in which the builder agrees with the government on the ex ante approval of $e$ at time 2. In this case, any chosen $e$ will be adopted at time 3 without going through further negotiation, so the government will sign a contract with the manager to implement the efficient level $\widetilde{e}(a)$. Thus, the agreement in the time-2 negotiation creates net surplus, which is

$$
\left\{[v(\widetilde{e})-C(a, \widetilde{e})-\widetilde{e}]-\left[v\left(e_{S B}^{O}\right)-C\left(a, e_{S B}^{O}\right)-e_{S B}^{O}\right]\right\}
$$

thus, through Nash bargaining, the builder is going to obtain one half of this net surplus plus his threat point payoff $f_{b}^{O}$ (defined in (4) and evaluated at $e=e_{S B}^{O}$ ). In other words, his net gains in the operating stage are

$$
\frac{1}{2}\left[v(\widetilde{e})-C(a, \widetilde{e})+C(a, 0)+e_{S B}^{O}-\widetilde{e}\right] .
$$

time 1 Being the owner, the builder will unilaterally implement his chosen $a$, because he always gets a positive payoff and in accordance with Bennett and Iossa (2006), the owner cannot commit not to implement his own investment.

time 0.5 When the builder decides on $a$, he knows that his chosen $a$ will be adopted. Therefore, his objective is simply to maximize $f_{b}$, which is the residual value plus his net gains in the operating stage (defined in (6)), minus the cost of investment $a$.

$$
f_{b}=R(a)+\frac{1}{2}\left[v(\widetilde{e})-C(a, \widetilde{e})+C(a, 0)+e_{S B}^{O}-\widetilde{e}\right]-a
$$

Hence, understanding that both $\widetilde{e}$ and $e_{S B}^{O}$ are functions of his choice, his optimal choice $a_{S B}$ satisfies

$t^{\prime}\left(a_{S B}\right)+\frac{1}{2}\left[d_{1}\left(a_{S B}, \widetilde{e}\right)-d_{1}\left(a_{S B}, 0\right)+\frac{d e_{S B}^{O}}{d a}\right]+\frac{1}{2}\left[v^{\prime}(\widetilde{e})+d_{2}\left(a_{S B}, \widetilde{e}\right)-1\right] \frac{d \widetilde{e}}{d a}=1$.

\footnotetext{
${ }^{13}$ The transfer to the builder is paid in the negotiation that happens at time 3 ; the transfer to the manager is paid when the complete contract is signed at time 2 , and the exact payment is to cover all the costs of the manager.
} 
Making use of (3), we obtain

$$
t^{\prime}\left(a_{S B}\right)+\frac{1}{2}\left[d_{1}\left(a_{S B}, \widetilde{e}\right)-d_{1}\left(a_{S B}, 0\right)\right]+\frac{1}{2} \frac{\partial e_{S B}^{O}}{\partial a}=1 .
$$

Since $a_{S B}$, together with $\widetilde{e}$ and $e_{S B}$, is determined by (3), (5), and (7), there are several interesting observations. First, the function $u($.$) does not appear in any of the$ three equations, and hence $a_{S B}$ is independent of $u($.$) . In other words, the builder$ fails to internalize the social benefit of his investment. Second, totally differentiating (5), we obtain

$$
\frac{\partial e_{S B}^{O}}{\partial a}=-\frac{d_{21}\left(a, e_{S B}^{O}\right)}{v^{\prime \prime}\left(e_{S B}^{O}\right)+d_{22}\left(a, e_{S B}^{O}\right)} .
$$

It indicates that, an increase in $a$ leads to an increase in $e_{S B}^{O}$ in case of complementarity and to a reduction of $e_{S B}^{O}$ in case of substitutability.

Third, from (7), $a_{S B}$ is increased by task complementarity (when $\partial e_{S B}^{O} / \partial a>0$ and $\left.d_{1}\left(a_{S B}, \widetilde{e}\right)-d_{1}\left(a_{S B}, 0\right)>0\right)$ and is decreased by task substitutability (when $\partial e_{S B}^{O} / \partial a<0$ and $\left.d_{1}\left(a_{S B}, \widetilde{e}\right)-d_{1}\left(a_{S B}, 0\right)<0\right)$. The intuition is that, through the negotiation with the government (at time 2), the builder shares the benefits generated by $e$, and his gains are in turn related to the default choice $e_{S B}^{O}$. In more detail, in the event of bargaining breakdown, a greater $e_{S B}^{O}$ enlarges the surplus equally shared between the government and the builder, while rising the cost of operating investment, which is borne by the government alone. So a greater $e_{S B}^{O}$ enhances the relative bargaining position of the builder. Thus, if $a$ and $e$ are complements, the solo builder is given additional incentive to invest $a_{S B}$ in order to induce the government to choose a higher level of $e_{S B}^{O}$. This explains why complementarity favors the investment of $a$ under the builder's ownership.

\subsubsection{Ownership by the consortium}

Suppose a consortium undertakes both building and operation and also owns the facility. To solve the game, we use backward induction. We first notice that, in the operating stage, once the consortium has chosen $e$, he will adopt it. The government is not concerned that such investment is not adopted. She however needs to be concerned whether the "right" level of investment is made. Given the interim contractibility of $e$, the government and consortium could negotiate on the level of investment $e$ prior to its choice (i.e., at time 2). If no agreement is achieved in such negotiation, the consortium would (at time 2.5) ignore the social benefit and set 
$e=e_{I C}^{O}(a)$, satisfying

$$
d_{2}\left(a, e_{I C}^{O}(a)\right)=1
$$

Totally differentiating (9), we obtain

$$
\frac{\partial e_{I C}^{O}}{\partial a}=-\frac{d_{21}\left(a, e_{I C}^{O}\right)}{d_{22}\left(a, e_{I C}^{O}\right)}
$$

Clearly, $e_{I C}^{O}(a) \leq \widetilde{e}(a)$. So the government and the consortium will sign a contract that leads to the efficient level $\widetilde{e}(a)$, which ensures the greatest surplus to be divided in negotiation (at time 2).

Back at the building stage. Analogical to the builder-ownership case, the investment $a$ would be adopted by the consortium without going through any bargaining. ${ }^{14}$ So at time 0.5 , the consortium will maximize his payoff by choosing $a=a_{I C}$, which satisfies

$$
t^{\prime}\left(a_{I C}\right)+\frac{1}{2}\left[d_{1}\left(a_{I C}, \widetilde{e}\right)+d_{1}\left(a_{I C}, e_{I C}^{O}\right)\right]-\frac{1}{2} v^{\prime}\left(e_{I C}^{O}\right) \frac{\partial e_{I C}^{O}}{\partial a}=1 .
$$

(See Appendix A for detailed derivation.)

Notice that $a_{I C}$, together with $\widetilde{e}$ and $e_{I C}^{O}$, is determined by (3), (9), and (11). There are two interesting observations. First, the function $u($.$) does not appear in$ any of the three equations. Hence, $a_{I C}$ is independent of $u($.$) , which means that the$ consortium also fails to internalize the social benefit of $a$. Second, from (11), $a_{I C}$ is decreased by task complementarity (when $\partial e_{I C}^{O} / \partial a>0$ ) and is increased by task substitutability (when $\partial e_{I C}^{O} / \partial a<0$ ). The intuition is that, the consortium's gains from the bargaining with the government (at time 2) depend on his default choice $e_{I C}^{O}$. A higher level of $e_{I C}^{O}$ implies less improvement in social benefits through the bargaining, enhancing the relative bargaining position of the government. ${ }^{15}$ Thus, if $a$ and $e$ are complements, the consortium would further underinvest $a_{I C}$, in order to lower the default choice of $e_{I C}^{O}$ and to extract more subsidies from the government.

In summary, in both $S B$ and $I C$ regimes, while the social benefit of $a$ is equally ignored, the task interdependence plays contrasting roles in the determination of $a$.

\footnotetext{
${ }^{14}$ As guaranteed by $\mathbf{A 1}$, the adoption of $a$ always yields positive gains to consortium, so the bargaining does not occur on this issue.

${ }^{15}$ Although an increase in $e_{I C}^{O}$ lowers the operational cost and this effect benefits the consortium, it incurs more costs of operating investment borne by the consortium alone. As shown in (9), when the consortium chooses $e_{I C}^{O}$ to maximize his threat point payoff, these two effects are cancelled out in the marginal level. So we have explained that an increase in $e_{I C}^{O}$ is less likely to enhance the bargaining position of the consortium than that of the government.
} 


\subsection{Investment under public ownership}

\subsubsection{Separation and public ownership}

Suppose that the builder and the manager are two separate agents, and that the government is the owner of the facility. We use backward induction. First consider the operating stage. When the government contracts (at time 2) with the manager, she has already internalized all the benefits and costs generated by $e$. As a result, she chooses the efficient level, $\widetilde{e}(a)$, which satisfies (3); it is simply meaningless to adjust to any other level of $e$.

We then move back to the building stage. Subsequent to the choice of $a$, there is a negotiation between the builder and the government on its adoption. If $a$ is not adopted, the builder ends up with nothing except the default contract payment, while the government has to set $e=\widetilde{e}(0)$ and ends up with a continuation payoff $[R(0)+B(0, \widetilde{e}(0))-C(0, \widetilde{e}(0))-\widetilde{e}(0)] \cdot{ }^{16}$ However, if the two parties reach an agreement on the adoption of $a$, the total surplus generated is $[R(a)+B(a, \widetilde{e}(a))-C(a, \widetilde{e}(a))-\widetilde{e}(a)]$. Using the Nash bargaining solution, the payoff of the builder is denoted by $f_{b}$ and calculated as follows.

$$
\begin{aligned}
f_{b}= & \frac{1}{2}[t(a)+u(a)+v(\widetilde{e}(a))+d(a, \widetilde{e}(a))-\widetilde{e}(a) \\
& -v(\widetilde{e}(0))-d(0, \widetilde{e}(0))+\widetilde{e}(0)]-a .
\end{aligned}
$$

Anticipating such bargaining and its impact, the builder will maximize $f_{b}$ subject to (3) by choosing $a=a_{S P}$, which satisfies

$$
\frac{1}{2}\left[u^{\prime}\left(a_{S P}\right)+t^{\prime}\left(a_{S P}\right)+d_{1}\left(a_{S P}, \widetilde{e}\right)\right]=1 .
$$

Altogether, $a_{S P}$, as well as $\widetilde{e}$, is determined by (3) and (12). Compared with the first-order condition for the first-best $a^{*}$, we find that now the marginal benefit of investing $a$ is half as under the first-best case. Consequently, $a_{S P}<a^{*}$. In contrast with private ownership, now the social benefit of $a$, represented by $u($.$) , is taken$ into account. Nonetheless, task interdependence is irrelevant. The underlying reason traces to the following facts: through the negotiation with the government (at time 1 ), the builder may share some benefits generated by investment $e$; however, in such bargaining, the threat point of the builder is defined by the payoff when $a_{S P}$ is not

\footnotetext{
${ }^{16}$ Since the government could sign a complete contract with the manager to implement $\widetilde{e}(0)$ (and there are no frictions in contracting), the former party would perfectly internalize the payoff of the latter party. In particular, the transfer made from the government to the manager could only cover the costs incurring to the latter party, which is $[C(0, \widetilde{e}(0))+\widetilde{e}(0)]$.
} 
adopted (i.e., $a=0$ ), so his relative bargaining position is independent of the choice of $a_{S P}$ as well as the interaction between $a$ and $e$.

\subsubsection{Integration and public ownership}

Suppose that a consortium is in charge of the building and operation, and that the government has the ownership. In contrast with the $S P$ regime, the negotiations in the $I P$ regime are triggered not only by the adoption of investment $a$, but also by the contracting of investment $e$. Nonetheless, in what follows, we will show that these two regimes are equivalent as far as the equilibrium choices of investments are concerned. While the detailed analysis is relegated to the Appendix A, we sketch an outline here.

First, consider the operating stage. The timing of events occurring in this stage is much similar with that depicted in Figure 2. If the agreement on the choice and adoption of $e$ is reached in the negotiation at time 2, the negotiation may not happen again at time 3 . But the latter negotiation determines the threat points of the former negotiation. In case that no ex ante approval on the adoption of $e$ is solicited from

government (at time 2), the consortium will at time 2.5 set $e=e_{I P}^{O}(a)$, which solves

$$
\frac{1}{2}\left[v^{\prime}\left(e_{I P}^{O}(a)\right)+d_{2}\left(a, e_{I P}^{O}(a)\right)\right]=1 .
$$

Totally differentiating (13), we obtain

$$
\frac{\partial e_{I P}^{O}}{\partial a}=-\frac{d_{21}\left(a, e_{I P}^{O}\right)}{v^{\prime \prime}\left(e_{I P}^{O}\right)+d_{22}\left(a, e_{I P}^{O}\right)} .
$$

Obviously, $e_{I P}^{O}(a)<\widetilde{e}(a)$ and it is beneficial for the government and the consortium to sign a contract that sets $e=\widetilde{e}(a)$ at the beginning of the operating stage (i.e., at time 2). Negotiation takes place accordingly. Given such bargaining and the bargaining triggered by the approval of $a$, the payoff of the consortium is calculated as follows.

$$
f=\frac{1}{2}\left[t(a)+u(a)+v(\widetilde{e}(a))+d(a, \widetilde{e}(a))-\widetilde{e}(a)-e_{I P}^{O}(0)\right]-a .
$$

Thus, the consortium maximizes $f$ subject to (3) and (13) by choosing $a=a_{I P}$, which satisfies

$$
\frac{1}{2}\left[u^{\prime}\left(a_{I P}\right)+t^{\prime}\left(a_{I P}\right)+d_{1}\left(a_{I P}, \widetilde{e}\right)\right]=1 .
$$

Altogether, $a_{I P}$, as well as $\widetilde{e}$, is determined by (3) and (16). Notice that $a_{I P}=a_{S P}<$ $a^{*}$, and the two regimes are equivalent in terms of investment choices. The underlying 
reason is that, under the public ownership, the government always has veto power on the ex post adoption of $a$, so negotiation happens on this issue and plays a key role in shaping the incentive of the investor in the building stage. Through such negotiation and given the interim contractibility, either the solo builder or the consortium could shares one half of the net surplus generated by $a$, while his threat point is independent of the choice of $a$. These facts, altogether, explain that the difference between the regimes on the choice of $a$ vanishes.

\subsection{Optimal regime}

Interim contractibility of $e$, which ensures that $e$ is always efficiently chosen, allows us to focus solely on $a$ in our comparison of alternative regimes. In case of underinvestment of $a$ in all alternative regimes, the optimal regime is the one that yields the greatest $a$. We have already noted that, $a$ is obviously under-invested under the two public regimes considered and that the investments under the two private regimes considered are independent of social benefit effect of $a$, i.e., $u(a)$. However, the firstbest level $a^{*}$ is increasing in $u^{\prime}($.$) . Therefore, whenever u^{\prime}($.$) is high enough, there is$ under-investment in all regimes.

To facilitate the discussion, we can parameterize $u$ and $t$ (the residual value), by writing $u(a)=\rho U(a)$ and $t(a)=\omega T(a)$, where $U$ and $T$ are the benchmark

social benefit function and residual value function. An increase in $\rho$ (or $\omega$ ) means an increase in the importance of social benefit (or residual value) given $a$. We use $(\rho, \omega)$ to denote the problem under parameters $\rho$ and $\omega$.

Lemma 1 (1) Given $\omega$, there exists $\rho^{*}$ such that there is underinvestment of a in all regimes if and only if $\rho>\rho^{*}$.

(2) For all $\omega>0$, if there is underinvestment of a in all regimes under $(\rho, \omega)$, then there is also underinvestment of a under $\left(\rho, \omega^{\prime}\right)$, for any $\omega^{\prime}>0$ and $\omega^{\prime} \neq \omega$.

Proof. See the Appendix.

Part (1) suggests that whenever the social benefit of $a$ is sufficiently large (i.e., $\rho$ is sufficiently large), there always exists underinvestment problem, since such effect is not fully internalized by the investors. Part (2) suggests that the cutoff $\rho^{*}$ is independent of $\omega$; or the residual value function $t$ (.) does not play any role in determining whether there is underinvestment of $a$ in all regimes. The role of part (2) will be made clearer soon.

The following proposition tells us whether bundling or unbundling of the two tasks is more desirable. 
Proposition 1 Suppose that a is non-contractible, $e$ is interim contractible, and $\rho>\rho^{*}$.

(1) Under private ownership, integration is better than separation for inducing both $a$ and $e$, if and only if, for all $a \in\left[\min \left[a_{I C}, a_{S B}\right], \max \left[a_{I C}, a_{S B}\right]\right]$,

$$
d_{1}\left(a, e_{I C}^{O}\right)+d_{1}(a, 0)>-\frac{d_{21}\left(a, e_{S B}^{O}\right)}{v^{\prime \prime}\left(e_{S B}^{O}\right)+d_{22}\left(a, e_{S B}^{O}\right)}-v^{\prime}\left(e_{I C}^{O}\right) \frac{d_{21}\left(a, e_{I C}^{O}\right)}{d_{22}\left(a, e_{I C}^{O}\right)},
$$

where $e_{I C}^{O}$ and $e_{S B}^{O}$ are defined by (9) and (5), respectively.

(2) Under public ownership, integration is equivalent to separation for inducing both $a$ and $e$.

Proof. See the Appendix.

We first consider part (1) of this proposition. Regarding (17), we notice that the left hand side, LHS, is positive if and only if investment $a$ has a cost-reduction effect on the operating stage. We can also verify that the right hand side, RHS, is positive (negative) if there is complementarity (substitutability) between $a$ and $e$. In other words, complementarity between investments makes it more difficult for integration to dominate separation under private ownership, while substitutability makes it easier. Thus, under private ownership, the desirability of bundling depends on both the externality measured by the partial derivative $d_{1}(a, e)$ and the task interdependence measured by cross derivatives $d_{21}(a, e)$.

The role of $a$ 's cost-reduction effect can be understood as follows. Suppose $d_{1}(a, e)>0$. When deciding how much to invest in the building stage, the consortium under integration is able to internalize the savings on operational costs, while the builder under separation is not able to. ${ }^{17}$ Thus, a larger cost-reduction effect of $a$ strengthens the incentive of the consortium, but not that of the builder. This part of the result is consistent with that in Bennett and Iossa (2006) and also in Martimort and Pouyet (2008).

The other part of the result is counter-intuitive, however. Despite a kind of positive externality, task complementary favors separation over integration under the private ownership. The key to understanding relies on the fact that the government may negotiate the choice of the operating investment with the builder or the consortium at the interim stage (especially when its default choice deviates from the

\footnotetext{
${ }^{17}$ Although the builder can bargain with the government in the $S B$ case, the threat points are defined by the payoffs after the adoption of $a$. The reason is that such bargaining is over contracting of $e$ at time 2, instead of adoption of $a$ at time 1. Thus, the builder cannot internalize the savings on operational costs through such bargaining.
} 
efficient level). Consider the task complementary. In case of unbundling, the builder would be happy if the default choice of operating investment is higher. The reason is that when negotiating it to the efficient level, a higher default level enables the builder to share less costs of the operating investment but more benefits generated. This explains why the builder invests more in order to enhance the default choice of operating investment as well as his bargaining position. However, in case of bundling, the consortium would be unhappy if the default choice of the operating investment is higher, since it reduces the subsidies exacted from the government when they recontract on the operating investment. Thus, he would further underinvest in the building stage in order to secure a higher bargaining position consequently.

Now turn to part (2) of Proposition 1, which states that under public ownership, neither task interdependence nor externality continues to shape the trade-offs between integration and separation. The underlying reasons are three-folded. First, under the public ownership, the government always has a say on the ex post adoption of building investment, so the negotiation always happens on this issue. Second, in such negotiation, the threat points of all parties are determined by the payoffs when the building investment is not adopted; so it explains why such investment, as well as its interaction with the operating investment, cannot change its investor's bargaining position. Third, the interim contractibility of operating investment deprives the bargaining power of the manager in case of unbundling; that means, whenever bargaining takes place, the total surplus generated by the building investment is always shared between the two parties: the government and the builder (or consortium), which in turn explains that task externality plays no role in the distinction between the integration and the separation under the public ownership. ${ }^{18}$

The following proposition answers whether or not the project should be privately owned.

Proposition 2 Suppose that $a$ is non-contractible, $e$ is interim contractible, and $\rho>\rho^{*}$.

(1) Given the choice of integration, consortium ownership is better than public own-

\footnotetext{
${ }^{18}$ As for the impacts of externality under the public ownership, our result is in contrast with that in Bennett and Iossa (2006). In their model, since investment $e$ is assumed to be non-contractible all the time, the solo manager indirectly shares certain part of benefits generated by the adoption of $a$ under the $S P$ regime. This explains why, in case of positive externality, the incentive of solo builder is diluted, compared with the consortium. However, in our model, the interim contractibility of $e$ relieves the solo builder of such concern under the $S P$ regime, since the manager would no longer be able to appropriate any surplus generated by the adoption of $a$ due to complete contracting.
} 
ership for inducing both $a$ and $e$, if and only if, for all $a \in\left[\min \left\{a_{I C}, a_{I P}\right\}, \max \left\{a_{I C}, a_{I P}\right\}\right]$,

$$
t^{\prime}(a)-u^{\prime}(a)+d_{1}\left(a, e_{I C}^{O}\right)>-v^{\prime}\left(e_{I C}^{O}\right) \frac{d_{21}\left(a, e_{I C}^{O}\right)}{d_{22}\left(a, e_{I C}^{O}\right)},
$$

where $e_{I C}^{O}$ is defined by (9).

(2) Given the choice of separation, builder ownership is better than public ownership for inducing both $a$ and $e$, if and only if, for all $a \in\left[\min \left\{a_{S B}, a_{S P}\right\}, \max \left\{a_{S B}, a_{S P}\right\}\right]$,

$$
t^{\prime}(a)-u^{\prime}(a)-d_{1}(a, 0)>\frac{d_{21}\left(a, e_{S B}^{O}\right)}{v^{\prime \prime}\left(e_{S B}^{O}\right)+d_{22}\left(a, e_{S B}^{O}\right)},
$$

where $e_{S B}^{O}$ is defined by (5).

Proof. See the Appendix.

This proposition implies that, in case of interim contractibility of $e$, when the government considers whether the project should be privately owned, she should consider not only the residual value effect, the social benefit effect, and the costreduction effect of the building investment, but also task interdependence. ${ }^{19}$ The following statements are true according to Proposition 2.

(a) Whether the tasks are integrated or separated, a larger residual value effect favors private ownership, and a larger social benefit effect favors public ownership. This result is consistent with that in Bennett and Iossa (2006).

(b) When the two tasks are integrated (separated), a larger cost-reduction effect of the building investment consolidates (reduces) the advantage of consortium (builder) ownership, relative to public ownership.

(c) When the two tasks are integrated, greater investment complementarity (substitutability) attenuates (enhances) the advantage of consortium ownership relative to public ownership.

(d) When the two tasks are separated, greater investment complementarity (substitutability) enhances (attenuates) the advantage of builder ownership relative to public ownership.

\footnotetext{
${ }^{19}$ Result 2 of Lemma 1 ensures that the $t$ (.) function, or the coefficient $\omega$, does not play any role in determining whether $a$ is underinvested in all regimes. Hence, given integration, we can always choose a high (low) enough $\omega$ so that (i) $a$ is underinvested in all regimes and (ii) $I C$ ownership is better (worse) than public ownership. A similar claim holds when the $I C$ ownership is replaced by $S B$ ownership.
} 
We end with a few more comments. Firstly, the model presented here indeed reflects the frequent adaptation of contracts in PPPs. We attribute the driving force of this phenomenon to interim contractibility, rather than falling into a conventional discussion of the contract length. Provided that the contract is incomplete at the outset, the resolved complexity is more likely to trigger renegotiation of the contract terms. This point is also contrasted with that in Bajari and Tadelis (2001) and Ellman (2006) who considered the renegotiation of contracts as a response to the changes in demand or discovery of new service innovations. Secondly, provided that $e$ is interim contractible, the equilibrium choice of operating investment matches with the efficient level, but the incentive for building investment varies by virtue of investment interdependence. In the next section, we will discuss to what extent the results obtained here carry to the environment in which $e$ is always non-contractible.

\section{Non-contractibility}

We have shown that task interdependence not only matters in the determination of the optimal regime but also plays a counter-intuitive role. As this paper is partially motivated by Bennett and Iossa (2006), it is useful to clarify whether the insights obtained in our framework are generalizable to theirs, where the sequential investments, $a$ and $e$, are both non-contractible.

Analytically, one complication is that, without the assumption of interim contractibility, $e$ is commonly inefficiently chosen in any ownership regime. Then the determination of optimal regime requires comparison of both $a$ and $e$, and it is difficult without further specification of the model. However, if we focus solely on the building problem, there is more we can say about. In an earlier version of this paper (Chen and Chiu, 2009), we show that, in presence of task complementarity (substitutability), it is more (less) likely that unbundling yields a greater $a$ than bundling. If $a$ is underinvested in every possible regime and, from the government's point of view, $a$ is of far more importance than $e$, then it is indeed the case that separation is a more (less) desirable arrangement than integration under task complementarity (substitutability). In this sense, despite a somewhat different underlying reason, the counter-intuitive role of task interdependence holds true in Bennett and Iossa's model. The intuition is as follows.

First consider the separation cases with the builder's or the government's ownership. In these cases, since $e$ is non-contractible, its adoption predicates ex post bargaining, through which the builder can share partial benefits generated by the 
manager's investment while not bearing any cost of it. ${ }^{20}$ If $a$ and $e$ are complementary, a higher level of $a$ would lead to a more efficient level of $e$, enlarging the net surplus to be split in the bargaining. Thus, by expecting more rents to (directly or indirectly) be extracted from the manager, the builder would like to invest a greater level of $a$. However, under the integration case where a unified agent takes charge of building and operation, if the consortium invests a greater $a$, he would bear the full cost of investing a greater $e$ subsequently, while the benefit of such investment is shared by the government. Hence, at the margin, the consortium's incentive to invest $a$ is less enhanced by the complementarity than is the builder's incentive.

It is useful to revisit the example of Private Finance Initiative (PFI) schools mentioned in Bennett and Iossa (2006). According to a report by the Audit Commission (2003), the quality of traditionally procured schools is commonly better than that of PFI schools. ${ }^{21}$ Bennett and Iossa (2006) provide an explanation to this phenomenon by referring to the negative externality across the project phases. However, it is hard to believe that a well-built facility in the school would by itself increase the operational costs. Alternatively, more valuable assets may induce the school managers to exert more efforts to engage in maintenance, since failure to control vandalism now causes more to be damaged and costs more for repairs. If the school builder happens to be the manager (as under PFI), he may fear that more "managerial efforts" (instead of direct operational costs) would be put into the operating stage. ${ }^{22}$ On the contrary, a traditional procurement contract can relieve the school builder of such a concern. This alternative story, which seems plausible, shows that, when PFI is less favored, the tasks of construction and operation may exhibit certain degree of complementarity, instead of negative externality.

\section{Complete contracting}

Our analysis has found that under two variant models of incomplete contracting frameworks, bundling is disfavored by investment complementarity, it is natural to ask if the same insight still exists in a complete contracting framework. In a framework where both $a$ and $e$ are observable and contractible and no-renegotiation can be

\footnotetext{
${ }^{20}$ In the separation with public ownership case, the builder can bargain with the government to indirectly share the benefits generated by the manager.

${ }^{21}$ As stated in Bennett and Iossa (2006), PFI refers to the $I C$ regime and traditional procurement refers to the $S P$ regime.

${ }^{22}$ To better understand this point, it is also worthwhile distinguishing between the operational cost and the cost incurred by managerial effort. In the model of non-contractibility, the former cost is transferable and can be deferred for payment after the bargaining over the adoption of $e$; the latter cost cannot be transferred and has already been sunk before that bargaining.
} 
committed to, the government can simply enforce the first-best $a$ and $e$ using takeit-or-leave-it offers. In this sense, the organization structure becomes an irrelevant issue. To make the question more interesting, it would be useful to focus on models in which certain frictions, such as risk aversion and limited liability, are present in the contracting process. To this end, we first turn to Martimort and Pouyet (2008), who show that, in a complete contracting framework, the cost reduction effect of the building effort favors bundling over unbundling. Extending this model with task interdependence, we argue that integration tends to be favored by task complementarity, in contrast with our earlier result.

\subsection{Risk aversion}

We follow Martimort and Pouyet (2008) closely. In their problem, a building investment, $a$, and an operating investment, $e$, are undertaken in a sequence, with costs $a^{2} / 2$ and $e^{2} / 2$, respectively. We assume that, in case of integration, a unified agent is in charge of investing both $a$ and $e$; in case of separation, two agents, namely, builder and manager, are in charge of investing $a$ and $e$ respectively. (Since there is no renegotiation, we do not consider the regime where one agent is the owner and hires the other agent.) Given $a$ and $e$, the following building quality $(Q)$ and operational cost $(C)$ are resulted:

$$
\begin{aligned}
& Q=a+\varepsilon \\
& C=\eta-e-\delta a-\theta a e
\end{aligned}
$$

where $\varepsilon(\eta)$ are random shock normally distributed with mean zero $\left(\eta_{0}\right)$ and variance $\sigma_{\varepsilon}^{2}\left(\sigma_{\eta}^{2}\right)$, and $\delta$ and $\theta$ are two coefficients. When $\theta=0$, the model is exactly the same as Martimort and Pouyet (2008); in this case, $\delta>0(\delta<0)$ means positive (negative) externality across stages: an increase in $a$ leads to a reduction (an increase) in operational cost. The task interdependence is brought in by a non-zero $\theta$ : if $\theta>0$ $(\theta<0), a$ and $e$ are complementary (substitute) investments. ${ }^{23}$ The builder and the manager in the separation regime, as well as the builder-manager in the integration regime, have the same constant-absolute-risk-aversion utility function with coefficient $r .^{24}$

\footnotetext{
${ }^{23}$ When $\theta=0, a$ has cost reduction effect if and only if $\delta>0$. Notice that $\partial C / \partial a=-\delta-\theta e$. Once $\theta \neq 0, a$ has cost reduction effect if and only if $\delta>-\theta e$; that means, whether $a$ has cost reduction effect does not depend solely on $\delta$.

${ }^{24}$ We interpret that a single agent serves both the role of building and managing in the integration regime, as it is assumed in the main part of Martimort and Pouyet (2008). They also study the case of consortium in which the builder and the manager mutually risk insure each other. The role of risk
} 
Two remarks are in order here. First, we assume that, despite the non-contractibility of $a$ and $e$, the building quality $(Q)$ and operational cost $(C)$ are contractible. Equally important is that the parties are able to commit to no re-negotiation. This framework is thus rightly called a complete contracting framework. Second, we assume that there is social benefit associated with project, denoted by $S \times Q$, where $S$ is a parameter reflecting the size of the social benefit.

Following Martimort and Pouyet (2008), we restrict ourselves to linear contracts. Under the integration regime, the following linear contract is signed with the consortium (builder-manager):

$$
\Psi(Q, C)=\xi+\beta Q-\alpha C,
$$

where $\xi$ is interpreted as an aggregate fixed-fee payment and $\beta$ and $\alpha$ piece-rate parameters. Under the separation regime, a pair of linear contracts are signed with the builder $(b)$ and manager $(m)$, respectively,

$$
\Psi_{i}(Q, C)=\xi_{i}+\beta_{i} Q-\alpha_{i} C
$$

where $\xi_{i}$ is interpreted as a fixed-fee payment and $\beta_{i}$ and $\alpha_{i}$ piece-rate parameters, where $i=b, m$. Obviously, $\beta_{m}=0$, since the manager's investment, $e$, does not impact the quality and any non-zero $\beta_{m}$ would expose unnecessary risk to the manager.

Let $a^{I}$ and $e^{I}$ denote the consortium's choices under the integration regime; $a^{S}$ and $e^{S}$ denote the builder's and manager's choices under the separation regime.

Lemma 2 Given contracts as stipulated in (22) and (23), the equilibrium choices are given by:

$$
\begin{aligned}
a^{I} & =\beta+\delta \alpha+\theta e^{I} \alpha ; \\
e^{I} & =\alpha+\theta a^{I} \alpha . \\
a^{S} & =\beta_{b}+\delta \alpha_{b}+\theta e^{S} \alpha_{b} ; \\
e^{S} & =\alpha_{m}+\theta a^{S} \alpha_{m} .
\end{aligned}
$$

Proof. See the Appendix.

We can show the following proposition regarding the case of task complementarity.

Proposition 3 Suppose $\delta=0$ and $\theta>0$ and linear contracts are used. Consider any pair of contracts under separation so that the builder's and manager's individual

insurance among agents is well known in the literature (see, e.g., Varian, 1990; Itoh, 1994). Chiu and Chou (2009) is a recent piece applying this idea to organization design in the context of offshoring and outsourcing. 
rationality (IR) constraints just bind. Then there always exists a contract under integration so that the builder-manager's IR constraint is satisfied, the same risk premium under the separating contracts is paid, and the equilibrium choices satisfy: $a^{I}>a^{S}$ and $e^{I}>e^{S}$.

Proof. See the Appendix.

The proposition suggests that, if $a$ and $e$ are complementary investments, given any pair of unbundling contracts, we can always find a bundling contract that is more desirable in the sense that it generates the same level of distortion (i.e., risk premium) but induces a higher level of incentives. In other words, it gives an intuitive result that task complementarity favors integration over separation, in terms of alleviating the underinvestment problem. In other words, a unified agent is easier to be motivated since the agency cost is relatively lower in case of task complementarity.

The underlying rationale of the proposition is as follows. Notice that the risk premium under integration equals $\beta^{2} \delta_{\varepsilon}^{2}+\alpha^{2} \delta_{\eta}^{2}$, while the total risk premia under

separation equals $\beta_{b}^{2} \delta_{\varepsilon}^{2}+\left(\alpha_{b}^{2}+\alpha_{m}^{2}\right) \delta_{\eta}^{2}$. Suppose $\beta=\beta_{b}$. Then the equal-risk premium condition implies that $\alpha \geq \alpha_{b}$ and $\alpha \geq \alpha_{m}$, where the two equalities cannot hold at the same time. Using (24) to (27), we immediately conclude that $a^{S}<a^{I}$ and $e^{S}<e^{I}$. Therefore, despite the same risk premium and that the relevant IR constraints bind, the integration regime dominates the separating regime by better mitigating the underinvestment problem. The intuition is that, given the risk premium, under the separation regime, each agent is given a weaker incentive $\left(\alpha_{b} \leq \alpha\right.$ and $\left.\alpha_{m} \leq \alpha\right)$ to respond to the other agent's investment.

While Proposition 3 is concerned about task complementarity, the corresponding result regarding task substitutability is more difficult to obtain. The reason is that $a$ and $e$ normally change in opposite directions from one contractual regime to another, rendering the comparison difficult without further specification.

\subsection{Limited liability}

Despite the finding in the last subsection, the conventional understanding that task complementarity favors integration need not always hold even under complete contracting. Schmitz (2005) studies a sequential moral hazard model where control actions are contractible and limited liability is the source of agency problem. Assuming the effort in the first stage makes the effort in the second stage more effective (i.e., reduces the latter's marginal cost or increases its marginal benefit), the author finds that, when she needs to induce high efforts, the principal might need to pay a greater agency cost to the integrated agent under bundling than to the two separate agents 
under unbundling. ${ }^{25}$ In other words, this result predicts that task complementarity disfavors bundling.

Note that Schmitz's counter-intuitive result is due to the fact that the first-stage effort alters the agency rent generated by the second-stage effort. To a certain extent, this underlying force also exists in our interim contracting framework (as well as the incomplete contracting framework in Bennett and Iossa, 2006). It is nonetheless absent in Martimort and Pouyet (2008), since when moral hazard problem arises from risk aversion, premium is paid only to cover the agents' utility loss in bearing risks, and their utilities always match with their reservation levels. In this sense, the agency rent in the following stage cannot be altered by the investment in the previous stage.

\section{Conclusion}

This paper has reexamined the proper scope of public-private partnerships in the context of a project consisting of two tasks, such as construction and operation of a facility. The focus of analysis has been the role of task or investment interdependence, i.e., the two investments are either complements or substitutes. Whether the operation investment is non-contractible or interim contractible, we have found that investment interdependence is a determinant of the optimal PPPs. In particular, favored by the cost-reduction effect of the building investment, integration is nonetheless disfavored by investment complementarity. While the focus of this paper is on the interim contractibility framework, in which the second, operation task is contractible subsequent to the building stage, we have also argued that weaker but similar insights hold true in the incomplete contracting framework in the fashion of Bennett and Iossa (2006).

These findings regarding the role of task interdependence, while counter-intuitive, contributes to the understanding of one empirical puzzle raised in the literature. In a framework of investment externality but not investment interdependence, unbundled projects are rationalized by negative externality. Despite a theoretical possibility, examples of negative externality are relatively rare (see Iossa and Martimort, 2008). However, in our framework where investment interdependence is also allowed, unbundled projects can now be rationalized by weak positive externality together with strong complementarity. Our theory thus provides an alternative explanation to the

\footnotetext{
${ }^{25}$ According to Schmitz (2005), when tasks are bundled, the agent might be tempted to shirk in the first stage, since by doing so he could increase the rents obtained in the second stage. The underlying reason is that the agency rent resulting from limited liability problem becomes larger when the effect of effort on the success probability is reduced.
} 
phenomena. For example, the undesirable performance of PFI schools can be due to the fact that a better fitness might give rise to a higher value of guide service. In other cases involving high technology, such as IT projects, because more advanced and innovative system usually comes up with higher degree of complexity, more effort is required for the operator in learning how to handle it efficiently. The complementarity between building and operating thus weakens the advantage of bundling these tasks.

On the other hand, in such sectors as prison, waste disposal, transport and hospital, sequential investments of building and operating might exhibit certain level of substitutability. According to a report by National Audit Office (2003) in the United Kingdom, compared to traditional procurement, PFI prisons tend to improve performance and save costs. The reason is that innovative design solutions help reduce the level of staffing needed to ensure security in prison. The underlying reason may be the substitutability between building and operating, as much as the positive externality. In the waste disposal sector, a very well designed garbage-categorizing system may conceivably lessen the burden of garbage collectors and cleaners. According to our theory, bundling the tasks of designing and operating is favored in this case. In the transport sector, if an electronic eye system located in proper places along each highway is of very good quality, detection of speedsters may not demand much effort from the police or other rosters. Similarly, these tasks are better contracted out in a bundle. Because construction and management of many public projects often demonstrate interdependence, our model provides a greater latitude to understand and interpret real world phenomena.

We end with some comments on the role of the contracting framework. If project quality and cost are available for contracting upon but the agents are risk averse, the conventional insight that task complementarity favors bundling holds true. On the other hand, if agency problem stems from limited liability, or if the contract is incomplete to a certain degree (non-contractible or interim contractible) and ex post bargaining is unavoidable, it is possible that task complementarity favors unbundling. The lesson is that when delegating public project to private sectors, the government should condition her decisions on the features of contracting environment and agency problem. 


\section{References}

[1] Aghion, P., Tirole, J., 1994. The management of innovation. Quarterly Journal of Economics 109, 1185-1209.

[2] Audit Commission., 2003. PFI in Schools. The Audit Commission, London.

[3] Bajari, P., Tadelis, S., 2001. Incentives versus transaction costs: a theory of procurement contracts. RAND Journal of Economics 32, 387-407.

[4] Bennett, J., Iossa, E., 2006. Building and managing facilities for public services. Journal of Public Economics 90, 2143-2160.

[5] Besley, T., Ghatak, M., 2001. Government versus private ownership of public goods. Quarterly Journal of Economics 116, 1343-1372.

[6] Bentz, A., Grout, P.A., Halonen, M.L., 2001. What should the state buy? CMPO Working Paper No. 01/40, University of Bristol.

[7] Che, Y.-K., 2000. Can a contract solve hold-up when investments have externalities? a comment on De Fraja (1999). Games and Economic Behavior 33, 195-205.

[8] Chen, B., Chiu, Y.S., 2009. Public-private partnerships: task interdependence and contractibility. SSRN Working Paper.

[9] Chiu, Y.S., Chou, E.S., 2009. A theory of offshoring and outsourcing based on agency costs. Mimeo, University of Hong Kong and National Tsing Hua University.

[10] De Fraja, G., 1999. After you sir, hold-up, direct externalities, and sequential investment. Games and Economic Behavior 26, 22-39.

[11] Ellman, M., 2006. The optimal length of contracts with application to outsourcing. Discussion Paper Universitat Pompeu Fabra.

[12] Francesconi, M., Muthoo, A., 2006. Control rights in complex partnerships. Mimeo.

[13] Grossman, S.J., Hart, O.D., 1986. The costs and benefits of ownership: a theory of vertical and lateral integration. Journal of Political Economy 94, 691-719.

[14] Hart, O., 2003. Incomplete contracts and public ownership: remarks and an application to public-private partnerships. Economic Journal 119, 69-76. 
[15] Hart, O., Shleifer, A., Vishny, R., 1997. The proper scope of government: theory and an application to prisons. Quarterly Journal of Economics 112, 1119-58.

[16] Hoppe, E.I., Schmitz, P.W., 2008. Public versus private ownership: quantity contracts and the allocation of investment tasks. CEPR Discussion Paper.

[17] Iossa, E., Martimort, D., 2008. The simple micro-economics of public-private partnerships. Working paper.

[18] Itoh, H., 1994. Cooperation in hierarchical organizations: an incentive perspective. Journal of Law, Economics, and Organization 60, 410-427.

[19] Lulfesmann, C., 2004. Research collaborations with sequential investments. Economica $71,241-259$.

[20] Martimort, D., Pouyet, J., 2008. Build it not: normative and positive theories of public-private partnerships. International Journal of Industrial Organization, Special Issue on PPPs 26, 393-411.

[21] National Audit Office., 2003. PFI Construction Performance of Prisons. National Audit Office, London.

[22] Neher, D.V., 1999. Staged financing: an agency perspective. Review of Economic Studies 66, 255-274.

[23] Schmitz, P.W., 2005. Allocating control in agency problems with limited liability and sequential hidden actions. RAND Journal of Economics 36, 318-336.

[24] Smirnov, V., Wait, A., 2004. Hold-up and sequential specific investments. RAND Journal of Economics 35, 386-400.

[25] Varian, H., 1990. Monitoring agents with other agents. Journal of Institutional and Theoretical Economics 146, 153-174. 


\section{Appendix A: Detail about the first-order conditions de- rived in Section 3}

\section{A.1 Ownership by the consortium}

We solve the game by backward induction. The latest interesting time in this problem is at time 2. Due to the consortium's ownership, once $e$ is chosen at time 2.5, the consortium himself will adopt it at time 3 without going through any negotiation.

time 2 Now the government negotiates with the consortium on the choice of $e$, given the adopted $a$. In case that no agreement is reached, the consortium will choose $e=e_{I C}^{O}(a)$ satisfying $(9)$, and hence obtain $\left[-C\left(a, e_{I C}^{O}\right)-e_{I C}^{O}\right]$ in the operating

stage; in the meanwhile, the government obtains $v\left(e_{I C}^{O}\right)$. However, in case that the consortium agrees with the government to choose the efficient level $e=\widetilde{e}(a)$, the net surplus generated is

$$
\left\{v(\widetilde{e})-v\left(e_{I C}^{O}\right)-C(a, \widetilde{e})+C\left(a, e_{I C}^{O}\right)-\widetilde{e}+e_{I C}^{O}\right\}
$$

Through the Nash bargaining, the net surplus is divided equally, and the consortium accepts one half of it in exchange for agreeing to choose $\widetilde{e}(a)$. So the consortium's net gains in the operating stage are

$$
\frac{1}{2}\left\{v(\widetilde{e})-v\left(e_{I C}^{O}\right)-C(a, \widetilde{e})-C\left(a, e_{I C}^{O}\right)-\widetilde{e}-e_{I C}^{O}\right\}
$$

time 1 The investment $a$ would be adopted without any negotiation occurring.

time 0.5 At this time, the consortium's objective is to choose $a$ to maximize $f$ as follows.

$$
f=R(a)+\frac{1}{2}\left\{v(\widetilde{e})-v\left(e_{I C}^{O}\right)-C(a, \widetilde{e})-C\left(a, e_{I C}^{O}\right)-\widetilde{e}-e_{I C}^{O}\right\}-a .
$$

Subject to $\widetilde{e}$ satisfying (3) and $e_{I C}^{O}$ satisfying (9), the first-order condition is (11) as stated in the main text.

\section{A.2 Integration and public ownership}

We solve the game by backward induction. 
time 3 Consider the subgame following the history that no agreement was signed at time 2 on the adoption of $e$. The government and the consortium would bargain over the adoption of $e$ now. If bargaining breaks down again, in the operating stage, the consortium bears the operational cost $C(a, 0)$ and the government obtains nothing; however, if agreement is reached and $e$ is adopted, the net surplus created is $[v(e)-C(a, e)+C(a, 0)]$. Hence, through Nash bargaining, sharing one half of net surplus, the consortium obtains $\frac{1}{2}[v(e)-C(a, e)-C(a, 0)]$ in this case.

time 2.5 If the agreement was reached in the time- 2 negotiation on the choice and adoption of $e$, the consortium only implements the contract signed with the government. However, if no agreement was reached before, the consortium will take his own discretion to choose $e$; in this case, he needs to maximize his net gains (after the negotiation at time 3 ), which are $\left\{\frac{1}{2}[v(e)-C(a, e)-C(a, 0)]-e\right\}$, so the optimal choice $e_{I P}^{O}$ satisfies the first-order condition (13), as stated in the main text.

time 2 Now the government negotiates with the consortium on the choice and subsequent adoption of $e$. If such bargaining breaks down, $e_{I P}^{O}$ will be chosen and adopted, the consortium's net gains in the operating stage are

$$
\left\{\frac{1}{2}\left[v\left(e_{I P}^{O}\right)-C\left(a, e_{I P}^{O}\right)-C(a, 0)\right]-e_{I P}^{O}\right\}
$$

and the government's net gains are $\frac{1}{2}\left[v\left(e_{I P}^{O}\right)-C\left(a, e_{I P}^{O}\right)+C(a, 0)\right]$. If the agreement is reached, they will choose $e=\widetilde{e}$ to maximize the surplus generated, which is $[v(\widetilde{e})-C(a, \widetilde{e})-\widetilde{e}]$. Thus, they will agree on $\widetilde{e}$ at time 2. Through Nash Bargaining and sharing the net surplus equally, in the operating stage, the consortium gains

$$
\frac{1}{2}\left[v(\widetilde{e})-C(a, \widetilde{e})-C(a, 0)-\widetilde{e}-e_{I P}^{O}\right]
$$

and the government gains $\frac{1}{2}\left[v(\widetilde{e})-C(a, \widetilde{e})+C(a, 0)-\widetilde{e}+e_{I P}^{O}\right]$.

time 1 At time 1, the consortium is negotiating with the government on the adoption of investment $a$. If such bargaining breaks down, the consortium will end up with a continuation payoff

$$
\frac{1}{2}\left[v(\widetilde{e}(0))-C(0, \widetilde{e}(0))-C(0,0)-\widetilde{e}(0)-e_{I P}^{O}(0)\right],
$$


while the government will end up with a continuation payoff

$$
\left\{\frac{1}{2}\left[v(\widetilde{e}(0))-C(0, \widetilde{e}(0))+C(0,0)-\widetilde{e}(0)+e_{I P}^{O}(0)\right]+R(0)\right\} .
$$

However, if the agreement is reached and $a$ is adopted, the total surplus created is

$$
[u(a)+v(\widetilde{e}(a))-C(a, \widetilde{e}(a))-\widetilde{e}(a)+R(a)]
$$

By using the Nash bargaining solution and dividing the net surplus equally, we could calculate the payoff of the consortium as exactly described in (15).

time 0.5 At time 0.5 , the consortium chooses $a=a_{I P}$ to maximize his payoff $f$ described in (15), subject to $\widetilde{e}$ satisfying (3), the first-order condition is exactly described in (16).

\section{Appendix B: Proofs}

\section{B.1 Proof of Lemma 1}

Proof. Part (1). Compare (1), where $a^{*}$ is solved, with (12) and (16), where $a_{S P}$ and $a_{I P}$ are solved. Notice that they are identical except for a one-half coefficient in the LHS of the latter two equations (as a function of $a, e^{*}$ in (1) and $\widetilde{e}$ in (12) and (16) are the same). As a result, $a^{*}>a_{S P}=a_{I P}$, and no additional condition is needed to ensure the underinvestment of $a$ under public ownership regimes. Next notice that under the "ownership by the builder" case, $a_{S B}$, along with $e_{S B}^{O}$ and $\widetilde{e}$, is determined by (7) and (5) and (3). It is interesting to notice that $u($.$) does not$ appear in any of these three equations, and hence, $a_{S B}$ is independent of $u($.$) . On$ the other hand, (1), where $a^{*}$ is solved, contains $u^{\prime}()=.\rho U^{\prime}($.$) in the LHS, and hence$ $a^{*}$ can be made to be arbitrarily large by increasing $\rho$. Hence, there must exist a finite $\rho^{*}$ so that for all $\rho>\rho^{*}, a_{S B}<a^{*}$. The case of "ownership by the consortium" regime is similar and omitted. The claim is thus proved.

Part (2). Note that the term $t^{\prime}($.$) appears in the first order conditions of solving$ $a^{*}, a_{S B}$ and $a_{I C}$. This means function $t($.$) does not play any role in affecting relative$ magnitude of these choices of $a$. Finally, as noticed earlier, the choices of $a$ under the two public ownership regimes are always less than $a^{*}$. Regarding this, $t($.$) also does$ not play any role as well. 


\section{B.2 Proof of Proposition 1}

Proof. We start with the first result. Suppose that $a_{I C}>a_{S B}$. Notice that all the second-order conditions are satisfied. Then, making use of the first-order condition for the choice of $a_{I C}$ (see (11)), we know that, for $a \in\left[a_{S B}, a_{I C}\right]$,

$$
t^{\prime}(a)+\frac{1}{2}\left[d_{1}(a, \widetilde{e}(a))+d_{1}\left(a, e_{I C}^{O}(a)\right)\right]-\frac{1}{2} v^{\prime}\left(e_{I C}^{O}(a)\right) \frac{\partial e_{I C}^{O}(a)}{\partial a} \geq 1
$$

where the equality holds only when $a=a_{I C}$; making use of the first-order condition for the choice of $a_{S B}$ (see (7)), we also know that, for $a \in\left[a_{S B}, a_{I C}\right]$,

$$
t^{\prime}(a)+\frac{1}{2}\left[d_{1}(a, \widetilde{e}(a))-d_{1}(a, 0)\right]+\frac{1}{2} \frac{\partial e_{S B}^{O}(a)}{\partial a} \leq 1,
$$

where the equality holds only when $a=a_{S B}$. Therefore, by subtracting the second inequality from the the first, we obtain the following result:

$a_{I C}>a_{S B} \Rightarrow d_{1}\left(a, e_{I C}^{O}(a)\right)+d_{1}(a, 0)>\frac{\partial e_{S B}^{O}(a)}{\partial a}+v^{\prime}\left(e_{I C}^{O}(a)\right) \frac{\partial e_{I C}^{O}(a)}{\partial a}$ for all $a \in\left[a_{S B}, a_{I C}\right]$.

Suppose that $a_{I C}<a_{S B}$. In the similar manner, we obtain the following result:

$a_{I C}<a_{S B} \Rightarrow d_{1}\left(a, e_{I C}^{O}(a)\right)+d_{1}(a, 0)<\frac{\partial e_{S B}^{O}(a)}{\partial a}+v^{\prime}\left(e_{I C}^{O}(a)\right) \frac{\partial e_{I C}^{O}(a)}{\partial a}$ for all $a \in\left[a_{I C}, a_{S B}\right]$.

Finally, by combining (28) and (29) and making use of (10) and (8), we obtain the claimed result.

The second result, i.e., the equivalence result under public ownership, is obtained in a similar manner by comparing (16) and (12) and the proof is omitted.

\section{B.3 Proof of Proposition 2}

Proof. We start with the first result. Suppose that $a_{I C}>a_{I P}$. Notice that all the second-order conditions are satisfied. Then, making use of the first-order condition for the choice of $a_{I C}$ (see (11)), we know that, for $a \in\left[a_{I P}, a_{I C}\right]$,

$$
t^{\prime}(a)+\frac{1}{2}\left[d_{1}(a, \widetilde{e}(a))+d_{1}\left(a, e_{I C}^{O}(a)\right)\right]-\frac{1}{2} v^{\prime}\left(e_{I C}^{O}(a)\right) \frac{\partial e_{I C}^{O}(a)}{\partial a} \geq 1
$$


where the equality holds only when $a=a_{I C}$; making use of the first-order condition for the choice of $a_{I P}$ (see (16)), we also know that, for all $a \in\left[a_{I P}, a_{I C}\right]$,

$$
\frac{1}{2}\left[u^{\prime}(a)+t^{\prime}(a)+d_{1}(a, \widetilde{e})\right] \leq 1,
$$

where the equality holds only when $a=a_{I P}$. Therefore, subtracting the second inequality from the first and rearranging, we obtain the following result:

$a_{I C}>a_{I P} \Rightarrow t^{\prime}(a)-u^{\prime}(a)+d_{1}\left(a, e_{I C}^{O}(a)\right)-v^{\prime}\left(e_{I C}^{O}(a)\right) \frac{\partial e_{I C}^{O}(a)}{\partial a}>0$ for all $a \in\left[a_{I P}, a_{I C}\right]$.

Suppose that $a_{I C}<a_{I P}$. In a similar manner, we could obtain the following result:

$a_{I C}<a_{I P} \Rightarrow t^{\prime}(a)-u^{\prime}(a)+d_{1}\left(a, e_{I C}^{O}(a)\right)-v^{\prime}\left(e_{I C}^{O}(a)\right) \frac{\partial e_{I C}^{O}(a)}{\partial a}<0$ for all $a \in\left[a_{I C}, a_{I P}\right]$

By combining (30) and (31), and making use of (10) we show the claimed result.

As for the second result, i.e., (19), it is obtained by comparing (7) and (12). The proof is much similar and hence omitted.

\section{B.4 Proof of Lemma 2}

Proof. In the bundling case, the consortium chooses $a=a^{I}$ and $e=e^{I}$ to maximize the following payoff

$$
f=\xi-\alpha \eta_{0}+\beta a+\alpha(e+\delta a+\theta a e)-\frac{1}{2} r\left(\beta^{2} \sigma_{\varepsilon}^{2}+\alpha^{2} \sigma_{\eta}^{2}\right)-\frac{1}{2} a^{2}-\frac{1}{2} e^{2} .
$$

(Notice that the risk premium generated in this sort of contract is $\frac{1}{2} r\left(\beta^{2} \sigma_{\varepsilon}^{2}+\alpha^{2} \sigma_{\eta}^{2}\right)$.) It can be verified that $a^{I}$ and $e^{I}$ as described in the Lemma are optimal. In the unbundling case, the builder chooses $a=a^{S}$ to maximize his payoff

$$
f_{b}=\xi_{b}-\alpha_{b} \eta_{0}+\beta_{b} a+\alpha_{b}(e+\delta a+\theta a e)-\frac{1}{2} r\left(\beta_{b}^{2} \sigma_{\varepsilon}^{2}+\alpha_{b}^{2} \sigma_{\eta}^{2}\right)-\frac{1}{2} a^{2}
$$

the manager chooses $e=e^{S}$ to maximize his payoff

$$
f_{m}=\xi_{m}-\alpha_{m} \eta_{0}+\alpha_{m}(e+\delta a+\theta a e)-\frac{1}{2} r\left(\alpha_{m}^{2} \sigma_{\eta}^{2}\right)-\frac{1}{2} e^{2} .
$$

It can be verified that $a^{S}$ and $e^{S}$ as described in the Lemma are optimal. 


\section{B.5 Proof of Proposition 3}

Proof. Let $\mathcal{C}_{b}\left(\beta_{b}, \alpha_{b}\right)$ and $\mathcal{C}_{m}\left(\beta_{m}=0, \alpha_{m}\right)$ be the contracts under separation that just satisfy the builder and manager's IR constraints. (The IR constraints are satisfied as long as the risk premia, which are independent of the actual investment choice, are included.) Suppose $\delta=0$. It is straightforward to show that the equilibrium choices can be represented by

$$
\begin{aligned}
a^{S} & =\phi\left(\beta_{b}, \alpha_{b}, \alpha_{m}\right) \equiv \frac{\beta_{b}+\theta \alpha_{b} \alpha_{m}}{1-\theta^{2} \alpha_{b} \alpha_{m}} \\
e^{S} & =\omega\left(\beta_{b}, \alpha_{b}, \alpha_{m}\right) \equiv \frac{\alpha_{m}\left(1+\theta \beta_{b}\right)}{1-\theta^{2} \alpha_{b} \alpha_{m}}
\end{aligned}
$$

Under integration, we can construct a grand contract $\mathcal{C}(\beta, \alpha)$ such that $\beta=\beta_{b}$ and $\alpha=\sqrt{\alpha_{b}^{2}+\alpha_{m}^{2}}>\max \left\{\left|\alpha_{b}\right|,\left|\alpha_{m}\right|\right\}$. One can verify that such a bundling contract $\mathcal{C}(\beta, \alpha)$ generates the same level of risk premium as the pair of unbundling contracts $\mathcal{C}_{b}\left(\beta_{b}, \alpha_{b}\right)$ and $\mathcal{C}_{m}\left(\beta_{m}=0, \alpha_{m}\right)$ in total, that is,

$$
\beta^{2} \delta_{\varepsilon}^{2}+\alpha^{2} \delta_{\eta}^{2}=\beta_{b}^{2} \delta_{\varepsilon}^{2}+\left(\alpha_{b}^{2}+\alpha_{m}^{2}\right) \delta_{\eta}^{2}
$$

However, if $\theta>0$, the equilibrium choices of the consortium with contract $\mathcal{C}(\beta, \alpha)$ can be represented by $a^{I}=\phi(\beta, \alpha, \alpha)>\phi\left(\beta_{b}, \alpha_{b}, \alpha_{m}\right)=a^{S}$, and $e^{I}=\omega(\beta, \alpha, \alpha)>$ $\omega\left(\beta_{b}, \alpha_{b}, \alpha_{m}\right)=e^{S}$. In other words, a grand contract $\mathcal{C}(\beta, \alpha)$, with $\xi$ equal to sum of investment costs, $\left(a^{I}\right)^{2} / 2+\left(e^{I}\right)^{2} / 2$, plus the equivalent risk premium, will be acceptable for the consortium, and will implement $a^{I}>a^{S}$ and $e^{I}>e^{S}$. 


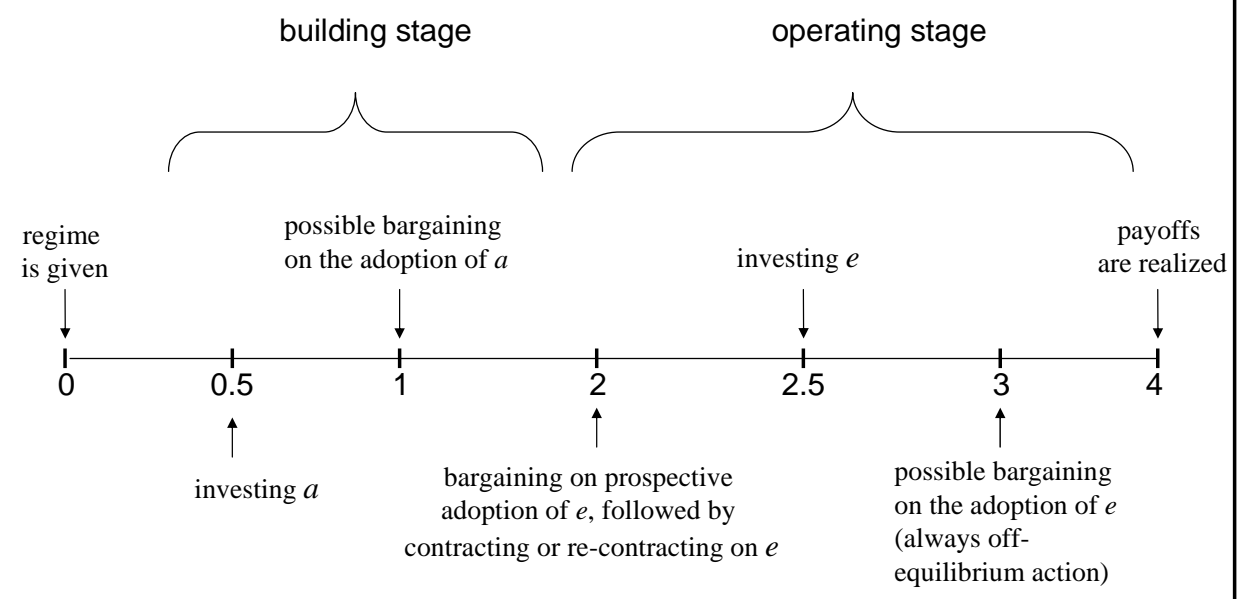

Figure 1: Time line of the game

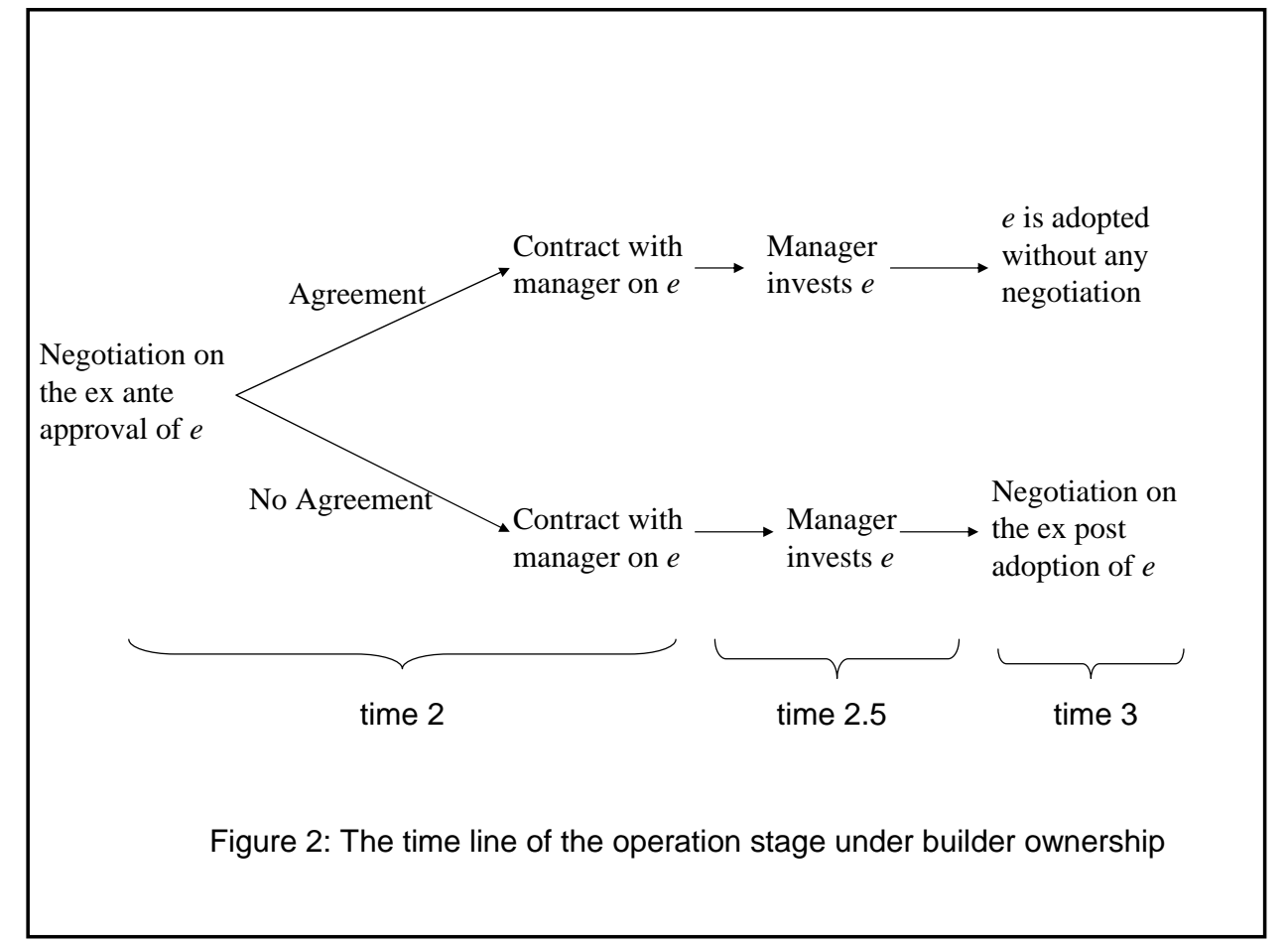

